\title{
Lung Cancer in a Rural Area of China: Rapid Rise in Incidence and Poor Improvement in Survival
}

\author{
Juan Yang ${ }^{1}$, Jian Zhu ${ }^{1}$, Yong-Hui Zhang ${ }^{1}$, Yong-Sheng Chen ${ }^{1}$, Lu-Lu Ding ${ }^{1}$, \\ Thomas W Kensler ${ }^{3,4}$, Jian-Guo Chen ${ }^{1,2}$
}

\begin{abstract}
Background: Lung cancer has been a major health problem in developed countries for several decades, and has emerged recently as the leading cause of cancer death in many developing countries. The incidence of lung cancer appears to be increasing more rapidly in rural than in urban areas of China. This paper presents the trends of lung cancer incidence and survival derived from a 40-year population-based cancer monitoring program in a rural area, Qidong, China. Materials and Methods: The Qidong cancer registration data of 19722011 were used to calculate the crude rate, age-standardized rate by Chinese population (CASR) and by world population (WASR), birth cohort rates, and other descriptive features. Active and passive methods were used to construct the data set, with a deadline of the latest follow-up of April 30, 2012. Results: The total number of lung cancer cases was 15,340 , accounting for $16.5 \%$ of all sites combined. The crude incidence rate, CASR and WASR of this cancer were 34.1, 15.7 and 25.4 per 100,000, respectively. Males had higher crude rates than females (49.7 vs 19.0). Rapidly increasing trends were found in annual percent change resulting in lung cancer being a number one cancer site after year 2010 in Qidong. Birth cohort analysis showed incidence rates have increased for all age groups over 24 years old. The 5 year observed survival rates were $3.55 \%$ in 1973-1977, 3.92 in $1983-1987,3.69 \%$ in 1993-1997, and 6.32\% in 2003-2007. Males experienced poorer survival than did females. Conclusions: Lung cancer has become a major cancer-related health problem in this rural area. The rapid increases in incidence likely result from an increased cigarette smoking rate and evolving environmental risk factors. Lung cancer survival, while showing some improvement in prognosis, still remains well below that observed in the developed areas of the world.
\end{abstract}

Keywords: Lung cancer - population-based cancer registry - incidence - observed survival - relative survival

Asian Pac J Cancer Prev, 16 (16), 7295-7302

\section{Introduction}

Lung cancer is the most commonly diagnosed cancer worldwide with more than 1.82 million cases and a standardized incidence rate of 23.1 per 100,000 estimated in 2012 (Ferlay et al., 2015a, http://globocan.iarc.fr). This cancer remains a major health problem in developed countries but incidence rates are now declining in many European and North American countries (Swerdlow et al., 1998; Simard et al., 2012; Kachuri et al., 2013). However, a continuing upwards trend of lung cancer incidence for many developing countries mandates greater attention to the implementation of global cancer control strategies (Shin et al., 2012; Chen et al., 2014). In China and other Asian countries, lung cancer has been the leading cause of cancer mortality for several years, and will remain so for the foreseeable future (Chen et al., 2014; Marugame et al., 2009; D'Souza et al., 2013). Moreover, rates of both incidence and mortality of lung cancer are increasing more rapidly in rural areas than in urban areas (Han et al., 2013; Cheng et al., 2013; Guo et al., 2012). These rural-urban differences in annual rate changes have been observed also in the United States and the United Kingdom, where the lung cancer mortality rates in non-metropolitan areas became even higher than in metropolitan areas after the mid 1980's (Singh et al., 2012; Gartner et al., 2011).

Lung cancer is difficult to treat, since it is often not discovered until the later stages of the disease. Surgery is usually used to treat earlier stage lung cancers, resulting in better prognosis for those identified in screening programs or in early detection settings. However, other factors are also associated with the prognosis of lung cancer patients, including age, tumor size, histological grade, and presence of visceral pleural invasion (Chen et al., 2013), old pulmonary tuberculosis lesions (Zhou et al., 2013), smoking status before illness (Mahesh et

${ }^{1}$ Qidong Liver Cancer Institute / Qidong People's Hospital, Qidong, ${ }^{2}$ Nantong University Tumour Hospital / Institute, Nantong, China ${ }^{3}$ Department of Pharmacology \& Chemical Biology, University of Pittsburgh, Pittsburgh, ${ }^{4}$ Department of Environmental Health Sciences, Johns Hopkins Bloomberg School of Public Health, Baltimore, USA *For correspondence: chenjg@vip.sina.com 
al., 2012; Nagakura et al., 2012), receipt of treatment, and socioeconomic inequalities or disparities in access to health care (Forrest et al., 2013).

Hence, the rates of lung cancer survival reported from clinical observations or hospital-based observations are unable to reflect the differences between or within countries or areas because of limitations in the number of patients who received various cancer therapies or in subsets of patients exhibiting various clinical characteristics. For assessing the overall efficiency of cancer health services in a given region or country, populationbased cancer survival data are strongly recommended (Sankaranarayanan et al., 2011). There are many reports referring to population-based cancer incidence data as well as survival data from western countries, such as the Cancer Incidence in Five Continents (Curado et al., 2009; Forman et al., 2014) and EUROCARE Study series (Berrino et al., 1995; De Angelis et al., 2014), as well as from Asian countries (Zeng et al., 2015; Roshandel et al., 2014; Varghese et al., 2014). However, long-term survival data adequate to describe and analyze the trends in incidence and survival of lung cancer, especial in rural areas, are rare.

Qidong has been long recognized as an endemic area for liver cancer, a circumstance that triggered the establishment of the Qidong Cancer Registry (QCR) over 40 years ago. Qidong, with a current and stable population of 1.12 million, has been a largely selfsufficient agricultural region until recently. However, the agricultural and economic isolation of Qidong began to dissipate in the late 1990s. Enormous transformations over the past decade have led Qidong to become a manufacturing center with a highly urbanized city center typical of modern coastal China. The continuous operation of the QCR provides the opportunity to examine trends of lung cancer incidence and survival over 4 decades using a population-based cancer monitoring registry initiated in a rural area in China.

\section{Materials and Methods}

\section{Case-finding}

The QCR is a population-based registry designated in 1972 as the cancer registration repository by the local health authority with compulsory reporting by health care workers. The Qidong All-death Cause Registration System has been an official vital statistics source approved by the Ministry of Health of China since 1974 (Chen et al., 2006; Zhao et al., 2012; Chen et al., 1991), with death from any cause reported by death certification notifications. Meeting the International Agency for Research on Cancer / International Association of Cancer Registries standards for quality, completeness, timeliness and unresolved duplicate records, the QCR is a member of the International Association of Cancer Registries. QCR data have been included in "Cancer Incidence in Five Continents" (CI5) (Ferlay et al., 2015a, http://globocan. iarc.fr; Forman et al., 2014; Parkin et al., 1997; Parkin et al., 2002) and other publications (Chen et al., 2006; Zhao et al., 2012).

\section{Case Follow-up}

The QCR uses both active and passive methods for cancer data collection and follow-up. All data files received from lower-level registries and all other hospitals or clinics are checked with cancer report lists and death certification notifications in order to track down missing cases and to exclude duplicate registrations. If the registry personnel receive the death notification first, the patient's medical records are reviewed or a home visit is carried out to obtain further information. The deadline of the latest follow-up for the data set used in this study was April 30,2012 . The survival duration of each case with lung cancer was determined as the time difference from the date of initial diagnosis to the date of death. The proportion of cases with morphological verification was $12.72 \%$ (1951/15340), with 41 lung cancer cases recognized by death certificate only.

Population, cancer classification and rate standardization The age distribution of the Qidong population is available from the sampling survey of 1976, and censuses of 1982, 1990, 2000, and 2010; proportional age distribution for each year was made by interpolating between these points. The International Classification of Diseases, 10th revision (ICD-10) was used for cancer classification. In this paper, lung cancer cases were those coded as C33-34 in the ICD-10. Crude rate (CR) was calculated by using population denominators. Age standardized rates by China population (CASR) 1964, and by world population 1960 were calculated; rates are expressed per 100,000 person-years, as described previously (Chen et al., 2006). The percent change in rates (r) over a particular time period is calculated by taking the difference between the average rate of the first 2 years ( $\mathrm{x}$, $\mathrm{x}+1)$ and the average rate of the last 2 years $(\mathrm{y}, \mathrm{y}-1)$, and dividing the difference by the average rate of the first 2 years, and multiplying by 100 to convert it to a percent. The annual percent change is calculated by fitting a least squares regression line to the natural logarithm $(\mathrm{Ln})$ of the $r$, using the calendar year $(x)$ as a regression variable (Chen et al., 2006).

\section{Survival rate calculation}

Cumulative observed survival rate (OS) and relative survival rate (RS) are calculated by using Hakulinen's SURV3.01 Software (http://www.cancer.fi/@ $\mathrm{Bin} / 54321472 /$ index.html). The result of RS is a ratio of survival rate for a group of patients with the same gender in the same age and the same period, i.e., $S_{c}(t)=S_{0}(t) /$ $S_{e}(t)$, where $S_{c}(t)$ is relative survival rate, $S o(t)$ is observed survival rate; $\mathrm{S}_{\mathrm{e}}(\mathrm{t})=\sum \mathrm{n}_{\mathrm{x}} \mathrm{S}_{\mathrm{ex}}(\mathrm{t}) / \sum \mathrm{n}_{\mathrm{x}}$, where $\mathrm{nx}$ is the number of patients being followed up at the age of $X, S_{e x}(t)$ is the survival rate at the time point $t$ of age $\mathrm{X}$. RS is calculated to exclude the chance of death from diseases other than this cancer. The expected survival rate for a group of people in the general population similar to the patient group with respect to gender, age and calendar registered year of observation was calculated using the Qidong life tables (Chen et al., 1998; Sankaranarayanan eds., 2011) for the years 1974-2011. 


\section{Results}

Crude incidence and age standardized rate

The total numbers of cancer for all sites during the period of 1972 to 2011 were 92,780, of which 15,340 were lung cancer $(16.53 \%)$. As such, lung cancer is the third leading cancer site for Qidongese after liver and stomach over this period. The crude incidence rate $(\mathrm{CR})$ of lung cancer was 34.12 per 100,000 population, and the truncated rate in 35-64 year olds was 36.96 per 100,000 . Table 1 indicates that there are marked upward trends for the CR, as well as CASR and WASR: from 9-16, 7-12, and $11-18$ per 100,000 in $1972-1975$ to $67-77,19-22$, and $32-36$ per 100,000 in 2008-2011, respectively. Since 2010 , lung cancer has been the number one cancer site in Qidong, with a CR of 76.09 per 100,000 in 2011.
Incidence rates by gender and the age-specific rate

Table 2 shows that the ratio of male to female incidence was 2.62:1, in which male cases were 11,028 , female cases 4312 , with crude rates of 49.67 per 100,000 for males, and 18.95 per 100,000 for females integrated over the 40 year period. Incidences in men and women increased rapidly from 11-21 and 7-12 per 100,000 in 1972-1975 to 97-110 and $36-46$ per 100,000 in $2008-2011$, respectively. The CASR and WASR have similar upwards trends during the period of 1972-2011.

The average incident ages of lung cancer were 66.22, 65.95, and 66.14 years for males, females, and both genders combined. Static between 1975 and 1999, there has been a steady increase in average incident age thereafter. The age-specific rates increase with age, peaking at 401.26, 111.81, and 234.75, per 100,000 for males, females, and both genders, within the age group of 75-79.

Table 1. Crude Rate, CASR, WASR, Truncated Rate and Cumulative Rate for Lung Cancer Incidence in Qidong, 1972-2011

\begin{tabular}{|c|c|c|c|c|c|c|c|c|}
\hline Year & No. Cases & $\begin{array}{c}\text { To All } \\
\text { Sites }(\%)\end{array}$ & $\begin{array}{c}\mathrm{CR} \\
\text { per } 100000\end{array}$ & $\begin{array}{c}\text { CASR } \\
\text { per } 100000\end{array}$ & $\begin{array}{c}\text { WASR } \\
\text { per } 100000\end{array}$ & $\begin{array}{c}\text { Truncated Rate of } \\
35-64 \text { per } 100000\end{array}$ & $\begin{array}{l}\text { Cum.Rate } \\
\text { of 0-74 (\%) }\end{array}$ & $\begin{array}{r}\text { Cum. } \\
\text { Risk (\%) }\end{array}$ \\
\hline$\overline{972}$ & 125 & 7.59 & 12.09 & 9.41 & 14.34 & 27.69 & 1.95 & 1.93 \\
\hline 1973 & 94 & 6.81 & 9.01 & 7.28 & 10.83 & 22.46 & 1.36 & 1.35 \\
\hline 1974 & 159 & 10.14 & 15.10 & 11.50 & 17.81 & 32.50 & 2.44 & 2.41 \\
\hline 1975 & 168 & 9.51 & 15.82 & 11.42 & 18.06 & 30.68 & 2.29 & 2.26 \\
\hline 1976 & 166 & 9.91 & 15.50 & 11.48 & 18.03 & 30.30 & 2.42 & 2.39 \\
\hline 1977 & 145 & 9.35 & 13.43 & 9.26 & 14.86 & 20.82 & 1.95 & 1.93 \\
\hline 1978 & 185 & 11.85 & 17.02 & 12.08 & 18.83 & 32.15 & 2.30 & 2.28 \\
\hline 1979 & 176 & 11.27 & 16.12 & 11.10 & 17.63 & 28.16 & 2.28 & 2.25 \\
\hline 1980 & 167 & 10.82 & 15.25 & 10.39 & 16.21 & 22.36 & 2.16 & 2.14 \\
\hline 1981 & 207 & 13.55 & 18.83 & 12.04 & 19.12 & 29.15 & 2.34 & 2.31 \\
\hline 1982 & 217 & 12.17 & 19.61 & 12.55 & 20.48 & 31.82 & 2.87 & 2.82 \\
\hline 1983 & 220 & 12.89 & 19.77 & 12.58 & 19.89 & 32.01 & 2.48 & 2.45 \\
\hline 1984 & 248 & 13.18 & 22.20 & 13.91 & 21.71 & 33.61 & 2.81 & 2.77 \\
\hline 1985 & 207 & 11.53 & 18.48 & 11.63 & 18.31 & 36.09 & 2.26 & 2.23 \\
\hline 1986 & 256 & 13.48 & 22.79 & 13.39 & 21.26 & 32.22 & 2.79 & 2.75 \\
\hline 1987 & 267 & 13.76 & 23.64 & 13.66 & 21.67 & 31.61 & 2.90 & 2.86 \\
\hline 1988 & 265 & 14.95 & 23.30 & 13.37 & 21.24 & 32.02 & 2.77 & 2.73 \\
\hline 1989 & 261 & 13.28 & 22.77 & 12.41 & 19.96 & 29.94 & 2.55 & 2.51 \\
\hline 1990 & 318 & 14.87 & 27.54 & 15.50 & 24.25 & 39.22 & 3.27 & 3.22 \\
\hline 1991 & 291 & 13.66 & 25.07 & 13.19 & 20.96 & 30.92 & 2.71 & 2.68 \\
\hline 1992 & 327 & 15.77 & 28.12 & 14.52 & 22.96 & 40.88 & 2.97 & 2.93 \\
\hline 1993 & 343 & 14.82 & 29.47 & 15.20 & 23.55 & 41.42 & 3.00 & 2.95 \\
\hline 1994 & 339 & 14.92 & 29.12 & 14.48 & 22.53 & 37.01 & 2.93 & 2.89 \\
\hline 1995 & 389 & 15.51 & 33.42 & 15.88 & 24.85 & 41.76 & 3.32 & 3.26 \\
\hline 1996 & 352 & 14.81 & 30.21 & 13.85 & 21.77 & 35.48 & 2.94 & 2.90 \\
\hline 1997 & 395 & 15.93 & 33.84 & 15.42 & 23.82 & 37.28 & 3.14 & 3.09 \\
\hline 1998 & 463 & 18.76 & 39.68 & 17.11 & 27.11 & 39.59 & 3.82 & 3.75 \\
\hline 1999 & 445 & 18.26 & 38.25 & 16.08 & 25.19 & 41.55 & 3.28 & 3.23 \\
\hline 2000 & 501 & 18.89 & 43.13 & 17.03 & 27.29 & 40.20 & 3.74 & 3.68 \\
\hline 2001 & 491 & 18.73 & 42.35 & 16.04 & 25.85 & 37.67 & 3.42 & 3.36 \\
\hline 2002 & 536 & 19.91 & 46.45 & 17.13 & 27.33 & 39.17 & 3.64 & 3.57 \\
\hline 2003 & 543 & 19.75 & 47.32 & 16.77 & 27.03 & 37.03 & 3.52 & 3.46 \\
\hline 2004 & 621 & 19.60 & 54.53 & 18.87 & 30.52 & 43.61 & 4.02 & 3.94 \\
\hline 2005 & 699 & 22.11 & 61.78 & 20.16 & 33.17 & 41.27 & 4.33 & 4.24 \\
\hline 2006 & 739 & 22.11 & 65.60 & 20.66 & 34.16 & 43.07 & 4.36 & 4.27 \\
\hline 2007 & 793 & 21.55 & 70.71 & 21.16 & 35.50 & 46.25 & 4.42 & 4.33 \\
\hline 2008 & 760 & 20.94 & 68.08 & 20.20 & 33.39 & 42.01 & 4.12 & 4.04 \\
\hline 2009 & 744 & 21.15 & 66.73 & 19.02 & 31.79 & 38.75 & 4.01 & 3.93 \\
\hline 2010 & 864 & 21.78 & 77.27 & 21.89 & 36.40 & 45.18 & 4.46 & 4.36 \\
\hline 2011 & 854 & 22.03 & 76.09 & 20.55 & 35.19 & 42.19 & 4.35 & 4.26 \\
\hline Total & 15340 & 16.53 & 34.12 & 15.74 & 25.41 & 36.96 & 3.27 & 3.22 \\
\hline
\end{tabular}


Table 2. Crude Rate, ASR per 100,000 by Gender for Lung Cancer in Qidong, 1972-2011

\begin{tabular}{|c|c|c|c|c|c|c|c|c|}
\hline \multirow[t]{2}{*}{ Year } & \multicolumn{4}{|c|}{ Male } & \multicolumn{4}{|c|}{ Female } \\
\hline & No. Cases & $\mathrm{CR}$ & CASR & WASR & No. Cases & $\mathrm{CR}$ & CASR & WASR \\
\hline 1972 & 86 & 16.97 & 14.30 & 21.82 & 39 & 7.40 & 5.32 & 8.24 \\
\hline 1973 & 55 & 10.76 & 9.34 & 13.94 & 39 & 7.34 & 5.58 & 8.23 \\
\hline 1974 & 95 & 18.37 & 15.37 & 23.84 & 64 & 11.95 & 8.27 & 12.83 \\
\hline 1975 & 109 & 20.87 & 16.85 & 26.39 & 59 & 10.93 & 6.89 & 11.21 \\
\hline 1976 & 108 & 20.48 & 16.55 & 26.07 & 58 & 10.67 & 7.30 & 11.41 \\
\hline 1977 & 90 & 16.93 & 12.92 & 20.87 & 55 & 10.04 & 6.26 & 10.02 \\
\hline 1978 & 114 & 21.30 & 16.94 & 26.23 & 71 & 12.87 & 7.89 & 12.56 \\
\hline 1979 & 117 & 21.76 & 16.46 & 26.39 & 59 & 10.65 & 6.65 & 10.53 \\
\hline 1980 & 121 & 22.49 & 16.39 & 26.32 & 46 & 8.25 & 5.53 & 8.38 \\
\hline 1981 & 135 & 24.99 & 17.69 & 28.83 & 72 & 12.87 & 7.43 & 11.56 \\
\hline 1982 & 153 & 28.03 & 19.63 & 32.57 & 64 & 11.41 & 6.72 & 10.87 \\
\hline 1983 & 161 & 29.32 & 20.10 & 32.40 & 59 & 10.46 & 6.35 & 9.92 \\
\hline 1984 & 184 & 33.38 & 22.65 & 35.75 & 64 & 11.31 & 6.53 & 10.27 \\
\hline 1985 & 164 & 29.61 & 20.04 & 32.08 & 43 & 7.59 & 4.36 & 6.85 \\
\hline 1986 & 173 & 31.13 & 19.63 & 31.95 & 83 & 14.62 & 8.26 & 12.86 \\
\hline 1987 & 183 & 32.77 & 21.01 & 33.31 & 84 & 14.71 & 7.18 & 11.76 \\
\hline 1988 & 186 & 33.04 & 20.44 & 33.09 & 79 & 13.75 & 7.34 & 11.44 \\
\hline 1989 & 189 & 33.30 & 19.57 & 32.14 & 72 & 12.44 & 6.35 & 10.15 \\
\hline 1990 & 234 & 40.90 & 24.48 & 39.33 & 84 & 14.42 & 7.71 & 11.76 \\
\hline 1991 & 199 & 34.57 & 19.22 & 31.52 & 92 & 15.73 & 7.98 & 12.27 \\
\hline 1992 & 246 & 42.61 & 23.27 & 37.56 & 81 & 13.83 & 6.61 & 10.23 \\
\hline 1993 & 249 & 43.05 & 23.04 & 36.39 & 94 & 16.06 & 7.93 & 12.10 \\
\hline 1994 & 249 & 43.09 & 21.85 & 34.97 & 90 & 15.35 & 7.65 & 11.34 \\
\hline 1995 & 307 & 53.22 & 26.09 & 41.56 & 82 & 13.96 & 6.20 & 9.45 \\
\hline 1996 & 274 & 47.39 & 22.18 & 35.53 & 78 & 13.28 & 5.90 & 9.01 \\
\hline 1997 & 291 & 50.24 & 23.27 & 36.40 & 104 & 17.69 & 7.76 & 11.92 \\
\hline 1998 & 361 & 62.44 & 27.08 & 43.50 & 102 & 17.33 & 7.45 & 11.59 \\
\hline 1999 & 328 & 56.91 & 24.71 & 38.66 & 117 & 19.93 & 7.43 & 11.90 \\
\hline 2000 & 360 & 62.51 & 24.47 & 40.27 & 141 & 24.07 & 9.79 & 15.10 \\
\hline 2001 & 355 & 61.81 & 23.66 & 38.71 & 136 & 23.25 & 8.61 & 13.57 \\
\hline 2002 & 409 & 71.53 & 26.87 & 43.46 & 127 & 21.81 & 7.76 & 12.24 \\
\hline 2003 & 402 & 70.71 & 25.49 & 41.63 & 141 & 24.35 & 8.44 & 13.38 \\
\hline 2004 & 445 & 79.06 & 27.86 & 46.06 & 176 & 30.55 & 10.36 & 16.20 \\
\hline 2005 & 501 & 89.70 & 30.10 & 50.40 & 198 & 34.56 & 10.89 & 17.54 \\
\hline 2006 & 526 & 94.62 & 30.16 & 51.53 & 213 & 37.32 & 12.00 & 18.92 \\
\hline 2007 & 570 & 103.06 & 31.69 & 54.37 & 223 & 39.24 & 11.58 & 18.97 \\
\hline 2008 & 555 & 100.87 & 30.84 & 52.04 & 205 & 36.22 & 10.54 & 17.05 \\
\hline 2009 & 535 & 97.48 & 28.51 & 49.05 & 209 & 36.92 & 10.56 & 16.84 \\
\hline 2010 & 605 & 110.05 & 32.62 & 55.04 & 259 & 45.57 & 12.18 & 20.10 \\
\hline 2011 & 604 & 109.54 & 30.82 & 54.00 & 250 & 43.79 & 11.45 & 19.19 \\
\hline Total & 11028 & 49.67 & 24.04 & 39.55 & 4312 & 18.95 & 8.34 & 13.22 \\
\hline
\end{tabular}

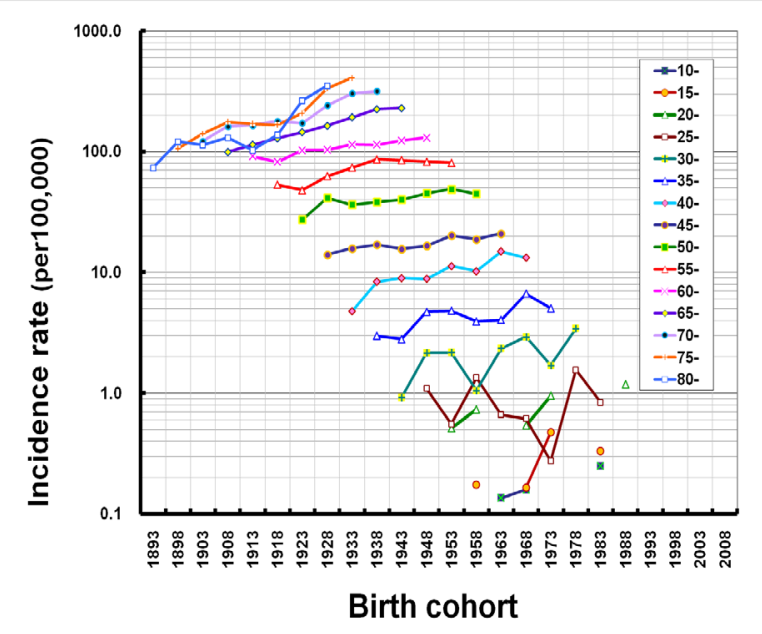

Figure 1. Incidence Rate for Lung Cancer by Birthcohort in Qidong, China, 1972-2011

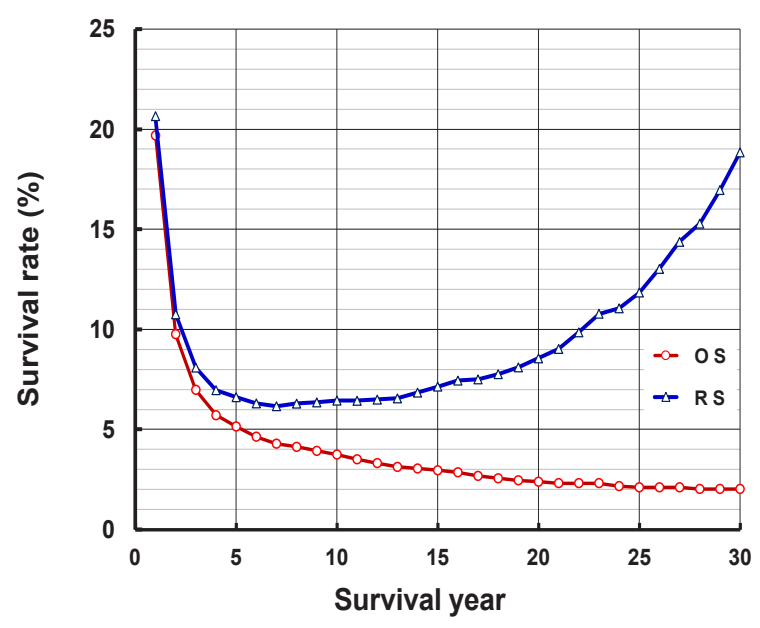

Figure 2. Observed Survival Rate and Relative Survival Rate of Lung Cancer in Qidong, China 
Table 3. Observed Survival Rate of Lung Cancer by Period in Qidong, 1972-2011 (\%)

\begin{tabular}{|c|c|c|c|c|c|c|c|c|}
\hline Surval year & 1973-1977 & 1978-1982 & 1983-1987 & 1988-1992 & 1993-1997 & 1998-2002 & 2003-2007 & 2008-2011 \\
\hline 1 & 19.95 & 15.97 & 13.86 & 14.02 & 14.52 & 19.95 & 21.68 & 26.28 \\
\hline 2 & 8.61 & 8.09 & 6.85 & 6.91 & 6.60 & 9.65 & 11.34 & 12.99 \\
\hline 3 & 5.60 & 5.46 & 5.26 & 4.51 & 4.79 & 6.69 & 8.72 & 8.62 \\
\hline 4 & 4.37 & 4.62 & 4.17 & 3.76 & 4.02 & 5.62 & 7.16 & 5.71 \\
\hline 5 & 3.55 & 4.10 & 3.92 & 3.56 & 3.69 & 5.13 & 6.32 & - \\
\hline 6 & 3.01 & 3.78 & 3.51 & 3.22 & 3.30 & 4.76 & 5.70 & \\
\hline 7 & 2.73 & 3.47 & 3.17 & 2.87 & 3.14 & 4.48 & 5.27 & \\
\hline 8 & 2.60 & 3.47 & 3.09 & 2.80 & 3.03 & 4.27 & 5.02 & \\
\hline 9 & 2.46 & 3.15 & 2.92 & 2.67 & 2.97 & 4.11 & 4.32 & \\
\hline 10 & 2.32 & 3.05 & 2.76 & 2.53 & 2.86 & 3.93 & - & \\
\hline 11 & 2.32 & 2.84 & 2.50 & 2.46 & 2.70 & 3.57 & & \\
\hline 12 & 1.78 & 2.73 & 2.50 & 2.33 & 2.64 & 3.47 & & \\
\hline 13 & 1.78 & 2.21 & 2.34 & 2.26 & 2.59 & 3.30 & & \\
\hline 14 & 1.78 & 1.89 & 2.25 & 2.26 & 2.59 & 3.30 & & \\
\hline 15 & 1.50 & 1.79 & 2.25 & 2.19 & 2.59 & - & & \\
\hline
\end{tabular}

\section{Birth cohort incidence and annual percent change}

Figure 1 shows the incidence of lung cancer by birth cohort during the years 1972-2011. It clearly features that incidence rates have been increasing in all birth cohorts over the age of 25. The percent changes (PC) of the CR, CASR, and WASR during the 40-year period were $626.68 \%, 154.31 \%$, and $184.35 \%$; the annual percent changes (APC) were, $4.92 \%, 2.05 \%$, and $2.21 \%$, respectively. The age-specific incidence rates increased gradually within all age groups 25 and older. In age group of $75+$, for instance, the specific rate rose from 52.94 per 100,000 in 1972 to 378.47 per 100,000 in $2008-2011$.

\section{Overall observed survival and relative survival}

The overall OS rates of 1-, 3-, 5-, 10-, 15-, 20-, and 30year were $19.69 \%, 6.98 \%, 5.15 \%, 3.75 \%, 2.96 \%, 2.39 \%$, and $2.03 \%$; and the RS rates were $20.65 \%, 8.09 \%, 6.61 \%$, $6.44 \%, 7.14 \%, 8.55 \%$, and $18.84 \%$, respectively. The OS and RS by year are shown in Figure 2 .

\section{Survival rate by gender, age and period}

Males experienced poor survival rates, with the OSs of $18.86 \%, 6.32 \%, 4.68 \%, 3.35 \%, 2.68 \%, 2.08 \%$, and $1.77 \%$ for 1-, 3-, 5-,10-, 15-, 20-, and 30-year survival; in females the rates were slightly improved to $21.81 \%, 8.73 \%, 6.36 \%$, $4.80 \%, 3.70 \%, 3.20 \%$, and $2.76 \%$, respectively. The RS rates show same tendency: rates were $19.85 \% 7.40 \%$, $6.14 \%, 6.00 \%, 6.95 \%, 8.32 \%$, and $20.13 \%$ in males and $22.66 \%, 9.82 \%, 7.78 \%, 7.43 \%, 7.55 \%, 9.08 \%$, and $18.10 \%$ in females, respectively. Overall, the survival rate from lung cancer decreased with age with a 5-year OS of 13.20 within the age group of 15-34, and of 2.21 in the age group of 75+. For RSs, these were 13.31 and 4.69 , respectively. Survival results by period during the 40 years give feature an unclear trend: the 5 year OSs were $3.55 \%$ in $1973-1977,4.10 \%$ in $1978-1982,3.92$ in $1983-$ $1987,3.56$ in $1988-1992,3.69 \%$ in $1993-1997,5.13 \%$ in $1998-2002$, and $6.32 \%$ in $2003-2007$. For the 10 -year OSs, the rates oscillated between $2.32 \%$ to $3.93 \%$ during the periods of 1973-1977 to 2003-2007. Table 3 indicates a slight improvement for OS by period, but it is still very poor over these four decades.

\section{Discussion}

The incidence of lung cancer used to be significantly higher in most industrialized areas worldwide compared with undeveloped countries. Now the burden of this disease is declining in some developed countries (Siegel $\mathrm{R}$ et al., 2014), but, due to the rising rates in developing countries, lung cancer has become the number one cancer worldwide (Parkin, 1994; Ferlay et al., 2015b). A study shows very high WASRs of lung cancer incidence in 2012, being among 149.4 - 373.9 per 100,000 in men, and 179.0 - 293.6 per 100000 in women in Australia, Brunei Darussalam, Japan, Korea, New Zealand, and Singapore (Varghese et al., 2014). In China, from 1991 to 2005 , lung cancer deaths in men have increased by $112 \%$, in which $62 \%$ is attributed to increased risk and $50.0 \%$ to aging of the population; in women by $154 \%$ (102\% due to the altered risk and $52 \%$ due to altered population demographics) (Yang et al., 2004). A recent report shows that the lung cancer crude incidence was 63.90 (CASR: 48.44) per 100,000 for males, and 31.93 (CASR: 21.93) per 100,000 for females in 2011 in China, ranking lung cancer first in all cancer sites in men, and second in women (Chen et al., 2015).

Lung cancer in China has experienced a continuous rising during the last 5 decades. For instance in metropolitan Shanghai, the crude mortality rates of lung cancer increased from 15.57 (WASR: 28.45) in 19631965 to 47.94 (55.53) per 100,000 in 1976-1977 (Gao et al., 1981); and the crude incidence rates increased in males and females from 63.55 and 26.21 in 1987 to 79.00 and 34.47 per 100,000 in 1997, respectively (Gao et al., 2007). In Beijing, lung cancer crude mortality has been shown the same increasing trends from 1977-1979 to 1983-1985 (Wang et al., 1990); in the years 2008-2012, the lung cancer incidence rates in urban and suburban areas were 61.23 , and 55.94 per 100,000 respectively (Yang et al., 2015). Increasing incidence rates are also reported in Zhejiang province (Mao, 2013) and in a rural area, Yanting county in Sichuan province, where the WASRs were 15.64 in 2004, and 26.06 per 100,000 in 2009 , with an APC of $12.86 \%$ (Li et al., 2011), showing the absolute rates are 
not so high but the upward trend is well defined.

In this 40 years perspective of the Qidong setting, we find that lung cancer has been rapidly rising with a CASR of 12.09 per 100,000 in 1972 and 76.09 in 2011 (Table 1). These values imply that the changes in rates for lung cancer have not only reflect aging of the Qidong population, but also changes in risk factors. What is noteworthy is that the crude incidence rates in recent years in this heretofore rural hinterland county have reached to over 100 per 100,000 in men, and over 40 per 100,000 in women, which surpasses the average lung cancer rate in China as a whole (Chen et al., 2015), and close to the levels reported in Shanghai and Beijing (Gao et al., 2007; Yang et al., 2015). The drivers for the increases in risk for this cancer are likely reflected in social changes, increasing urbanization, environmental pollution, and lifestyle evolution.

Risk factors of lung cancer have been known for decades: dust inhalation, radiation and radon gas and cigarette smoking (Ridge et al., 2013). Recent epidemiological surveys show that ambient air pollution contributes to risk of lung cancer (Raaschou-Nielsen et al., 2013), and is linked to exposure to urban air pollutants, mainly $\mathrm{PM}_{2.5}$ or $\mathrm{PM}_{10}$ and their components (Demetriou et al., 2015; Hamra et al., 2014). Smoking is very prevalent in men in Qidong and almost absent in women. Lung cancer incidence rates have increased linearly over the past four decades (Table 1), especially in men (Chen et al., 2014). Cigarette smoking could be a major cause of lung cancer as the rate of cigarette consumption per capita in men has increased in a similar linear fashion (Chen et al., 1991). However, other factors must be in play as there has been a doubling of lung cancer incidence in Qidongese women in the past decade following a 3-decade period of no change. With the evolving urbanization of the countryside within the circle of the Shanghai Economical Zone, regional air pollution has become a public health concern. Monitoring of air pollutants in the Yangtze River delta area show that there are no real differences in the levels of ambient air pollutants such as $\mathrm{PM}_{10}$ between Shanghai and Qidong in recent times (De Angelis et al., 2014). This may contribute to an explanation of why non-smoking women in this area also had increased lung cancer incidence close to the rate in Shanghai in the latest decade (Gao et al., 2007; Chen et al., 2014). We conclude from the current and past trends that lung cancer incidence in the Qidong area is likely to continue increasing in the absence of effective policies to mitigate smoking and exposures to air pollutants.

There are few reports referring to long term cancer survival rates especially in rural areas from populationbased cancer registration systems. In Qidong the 5-, $10-, 20-$, and 30 -year OSs were $5.15 \%, 3.75 \%, 2.39 \%$, and $2.03 \%$, and RSs were $6.61 \%, 6.44 \%, 8.55 \%$, and $18.84 \%$, respectively. Some progress in survival could be seen; for instance, the five-year OS was $6.32 \%$ in 2003-2007 compared to $3.55 \%$ in 1973-1977. However, these survival rates are poor compared with results from most Western countries, and some Asian countries. From a EUROCARE study the 5-year RS for the period of 1999-2007 was 13\%, ranging from $16.7 \%$ in Austria to $6.2 \%$ in Bulgaria (De Angelis et al., 2014). Previous reports indicated 5-year RSs of $14 \%$ to $28 \%$ in the US (Hayat et al., 2007), Germany (Brenner et al., 2005), Korea (Jung et al., 2007), and Japan (Tsukuma et al., 2006). In a recent global surveillance of cancer survival 1995-2009, 5-year survival from lung cancer was reported higher than $20 \%$ in only three countries: Japan (30\%), Israel (24\%), and Mauritius (37\%) (Allemani et al., 2015). In contrast, during the period of 2005-2009, the 5-year RSs were 2.2\%, $10.3 \%$, and $14.8 \%$ in African countries Libya, Tunisia, and Algeria, respectively, and were $4.4 \%, 6.6 \%, 8.1 \%$, $10.1 \%$, and $10.7 \%$ in Asian countries Jordan, Mongolia, Thailand, Turkey, and Malaysia (Allemani et al., 2015). These results suggest that lung cancer remains lethal in most countries, but exhibit disparities in survival between developed and developing countries.

Pooled analyses of cancer survival data of 2003-2005 from 17 registries in China showed that 5-year RS for lung cancer was $16.1 \%$. Patients from rural areas had a poorer rate of $11.2 \%$ compared to $19.5 \%$ for those from urban areas, likely due to their poor quality of cancer care and limited access to health care (Zeng et al., 2015). This is also true for Qidong. Recent improvement in transportation infrastructure allows patients with lung cancer easier access to big city hospitals (such as Shanghai). The available data from population-based cancer registries in Shanghai (Xiang et al., 1996) and Beijing (Wang et al., 2001) have showed that the 5-year RSs of lung cancer were between $11-12 \%$, while in a rural area Changle (Chen et al., 2000) in Southern China, it was $5.5 \%$ in men, and $3.9 \%$ for women. This poor survival is similar to our observations of $6.14 \%$ in men and $7.78 \%$ in women.

In conclusion, lung cancer has been rapidly increasing in rural area of Qidong during the last 4 decades, and may continue to rise in the foreseeable future. The poor survival from lung cancer in Qidong reflects a rural-urban disparity reflecting a lack in screening and early detection programs as well as limited options in the health care services. The recent urbanization of this region with an expanded cancer care infrastructure may lead to the improvement in survival of lung cancer in Qidong, but only if coupled with programs to reduce exposures to etiological factors..

\section{Acknowledgements}

We thank the Tumor Follow-up Registration Programs (MF2008-293, 2009-193, and 2010-90) supported by the National Central Cancer Registries of China, the National Science and Technology Mega-Projects of China 2012ZX100020009-018, and 2012ZX10002-008 and the US National Institutes of Health grant R01 CA190610 for funding.

\section{References}

Allemani C, Weir HK, Carreira H, et al (2015). Global surveillance of cancer survival 1995-2009: analysis of individual data for $25,676,887$ patients from 279 populationbased registries in 67 countries (CONCORD-2). Lancet, 385, 977-1010.

Berrino F, Sant M, Verdecchia A, eds (1995). Survival of cancer 
Lung Cancer in a Rural Area of China: Rapid Rise in Incidence and Poor Improvement in Survival

patients in Europe: the EUROCARE Study. IARC Sci Pub No, 132, 1-463.

Brenner H, Stegmaier C, Ziegler H (2005). Long-term survival of cancer patients in Germany achieved by the beginning of the third millenium. Ann Oncol, 16, 981-6.

Chen JG, Kensler TW (2014). Changing rates for liver and lung cancers in Qidong, China. Chem Res Toxicol, 27, 3-6.

Chen JG, Li WG, Shen ZC, et al (1998). Population-based cancer survival in Qidong, China. In: Sankaranarayanan R, Black R, Parkin DM, editors. Cancer Survival in Developing Countries. IARC Sci Pub No. 145. Lyon: IARC, 27-35.

Chen JG, Peto R, Sun ZT, et al (1991). Feasibility of a prospective study of smoking and mortality in Qidong, China. In: O'Neill IK, Chen J, Bartsch H, eds. Relevance to Human Cancer of N-Nitroso Compounds, Tobacco Smoke and Mycotoxins. IARC Sci Publ No. 105, Lyon: IARC, 502-6.

Chen JG, Zhu J, Parkin DM, et al (2006). Trends in the incidence of cancer in Qidong, China, 1978-2002. Int J Cancer, 119 , 1447-54.

Chen JS, Xiao JR, Chen ZC, et al (2000). Relative survival rate analysis of malignant cancers patient in Changle city. Chin Cancer, 9, 535-6.

Chen W, Zheng R, Zeng H, et al (2015). Annual report on status of cancer in China, 2011. Chin J Cancer Res, 27, 2-12.

Chen W, Zheng R, Zhang S, et al (2014). Annual report on status of cancer in China, 2010. Chin J Cancer Res, 26, 48-58.

Chen Z, Luo Q, Jian H, et al (2013). Long-term results of a randomized controlled trial evaluating preoperative chemotherapy in resectable non-small cell lung cancer. Onco Targets Ther, 6, 645-50.

Cheng L, Tan L, Zhang L, et al (2013). Chronic disease mortality in rural and urban residents in Hubei Province, China, 20082010. BMC Public Health, 13, 713.

Curado MP, Edwards B, Shin HR, et al (2009). Cancer Incidence in Five Continents. Vol IX. IARC Sci Pub No. 160. Lyon: IARC, 1-897.

De Angelis R, Sant M, Coleman MP, et al (2014). Cancer survival in Europe 1999-2007 by country and age: results of EUROCARE-5: a population-based study. Lancet Oncol, 15, 23-34.

Demetriou CA, Vineis $P$ (2015). Carcinogenicity of ambient air pollution: use of biomarkers, lessons learnt and future directions. J Thorac Dis, 7, 67-95.

D'Souza ND, Murthy NS, Aras RY (2013). Projection of cancer incident cases for India -till 2026. Asian Pac J Cancer Prev, 14, 4379-86.

Ferlay J, Soerjomataram I, Ervik M, et al (2015a): GLOBOCAN 2012 v1.0, Cancer Incidence and Mortality Worldwide: IARC CancerBase No. 11 [Internet]. Lyon, France: International Agency for Research on Cancer; Available from: http://globocan.iarc.fr. 18 May 2015.

Ferlay J, Soerjomataram I, Dikshit R, et al (2015b). Cancer incidence and mortality worldwide: sources, methods and major patterns in GLOBOCAN 2012. Int J Cancer, 136, 359-86.

Finnish Cancer Registry. SURV3: Windows Software for Relative Survival Analysis, http://www.cancer.fi/@ Bin/54321472/index.html, Accessed 25 May 2015.

Forman D, Bray F, Brewster DH, eds (2014). Cancer Incidence in Five Continents. Vol X. IARC Sci Pub No. 164. Lyon: IARC, 1-1435.

Forrest LF, Adams J, Wareham H,et al (2013). Socioeconomic inequalities in lung cancer treatment: systematic review and meta-analysis. Plos Med, 10, e1001376.

Gao YT, Lu W, eds (2007). Cancer Incidence, Mortality and Survival Rates in Urban Shanghai (1973-2000). Shanghai: Second Military Medical University Press, 1-443.
Gao YT, Tu JT, Jin F, et al (1981). Cancer mortality in Shanghai during the period 1963-77. Br J Cancer, 43, 183-95.

Gartner A, Farewell D, Roach $P$, et al (2011). Rural/urban mortality differences in England and Wales and the effect of deprivation adjustment. Soc Sci Med, 72, 1685-94.

Guo $P$, Huang ZL, Yu $P$, et al (2012). Trends in cancer mortality in China: an update. Ann Oncol, 23, 2755-62.

Hamra GB, Guha N, Cohen A, et al (2014). Outdoor particulate matter exposure and lung cancer: a systematic review and meta-analysis. Environ Health Persp, 22, 906-11.

Han R, Zheng R, Zhang S, et al (2013). Trend analyses on the differences of lung cancer incidence between gender, area and average age in China during 1989-2008. Zhongguo Fei Ai Za Zhi (Chin J Lung Can), 16, 445-51.

Hayat MJ, Howlader N, Reichman ME, et al (2007). Cancer statistics, trends, and multiple primary cancer analyses from the Surveillance, Epidemiology, and End Results (SEER) Program. Oncologist, 12, 20-37.

Jung KW, Yim SH, Kong HJ, et al (2007). Cancer survival in Korea 1993-2002: a population-based study. J Korean Med Sci, 22, 5-10.

Kachuri L, De $P$, Ellison LF, et al (2013). Cancer incidence, mortality and survival trends in Canada, 1970-2007. Chronic Dis Inj Can, 33, 69-80.

Li J, Song Q, Zhou X, et al (2011). Major cancer mortality and changes in Yanting, 2004-2009: introduction to cancer challenges in a high risk area. Asian Pac J Cancer Prev, 12, 409-13.

Mahesh PA, Archana S, Jayaraj BS, et al (2012). Factors affecting 30 -month survival in lung cancer patients. Indian $\mathrm{J}$ Med Res, 136, 614-21.

Mao WM, ed (2013). Cancer Incidence and Mortality in Registration Areas in Zhejiang Province 200-2009. Hangzhou: Zhejiang University Press. 1-162.

Marugame T, Matsuda T (2009). Comparison of time trends in lung cancer incidence (1973-2002) in Asia, from cancer incidence in five continents Vols IV-IX. Jpn J Clin Oncol, 39, 133-5.

Nagakura H, Nishikawa M, Kusano N, et al (2012). The impact of a negative history of smoking on survival in patients with non-small cell lung cancer detected with clinic-based screening programs. Intern Med, 51, 3115-8.

Parkin DM, Whelan SL, Ferlay J, et al (1997). Cancer Incidence in Five Continents, Vol. VII, IARC Sci Pub No. 143. Lyon: IARC.

Parkin DM, Whelan SL, Ferlay J, et al (2002). Cancer Incidence in Five Continents, Vol. VIII, IARC Sci Pub No. 155. Lyon: IARC.

Parkin DM (1994). Cancer in developing countries. Cancer Surv, 19-20, 519-61.

Raaschou-Nielsen O, Andersen ZJ, Beelen R, et al (2013). Air pollution and lung cancer incidence in 17 European cohorts: prospective analyses from the European Study of Cohorts for Air Pollution Effects (ESCAPE). Lancet Oncol, 14, 813-22.

Ridge CA, McErlean AM, Ginsberg MS (2013). Epidemiology of lung cancer. Semin Intervent Radiol, 30, 93-8.

Roshandel G, Boreiri M, Sadjadi A, et al (2014). A diversity of cancer incidence and mortality in west Asian populations. Ann Glob Health, 80, 346-57.

Sankaranarayanan R, Swaminathan R, eds (2011). Cancer Survival in Africa, Asia, the Caribbean and Central America. IARC Sci Publ No. 162, Lyon: IARC, 43-53.

Shin HR, Carlos MC, Varghese C (2012). Cancer control in the Asia Pacific region: current status and concerns. Jpn J Clin Oncol, 42, 867-81.

Siegel R, Ma J, Zou Z, et al (2014). Cancer statistics, 2014. CA Cancer J Clin, 64, 9-29. 
Simard EP, Ward EM, Siegel R, et al (2012). Cancers with increasing incidence trends in the United States: 1999 through 2008. CA Cancer J Clin, 62, 118-28.

Singh GK, Siahpush M, Williams SD (2012). Changing urbanization patterns in US lung cancer mortality, 19502007. J Community Health, 37, 412-20.

Swerdlow AJ, dos Santos Silva I, Reid A, et al (1998). Trends in cancer incidence and mortality in Scotland: description and possible explanations. Br J Cancer, 77, 1-54.

Tsukuma H, Ajiki W, Ioka A, et al (2006). Survival of cancer patients diagnosed between 1993 and 1996: a collaborative study of population-based cancer registries in Japan. Jpn J Clin Oncol, 36, 602-7.

Varghese C, Carlos MC, Shin HR (2014). Cancer burden and control in the Western pacific region: challenges and opportunities. Ann Glob Health, 80, 358-69.

Wang QJ, Zhu WX, Li L, et al (2001). Cancer Survival in Urban Beijing. Chin Cancer, 10, 263-4.

Wang QJ, Zhu WX (1990). Epidemiological features for lung cancer in Beijing. Chin J Cancer Res, 2, 49-51.

Xiang YB, Jin F, Chen HQ, et al (1996). An analysis of tumor patients' survival in Shanghai during 1988-1991. Chin Cancer, 5, 6-8.

Yang L, Parkin DM, Li LD, et al (2004). Estimation and projection of the national profile of cancer mortality in China: 1991-2005. Br J Cancer, 90, 2157-66.

Yang L, Yuan Y, Sun T, et al (2015). Population-based cancer incidence analysis in Beijing, 2008-2012. Chin J Cancer Res, 7, 13-21.

Zeng HM, Zeng RS, Guo YM, et al (2015). Cancer survival in China, 2003-2005: A population-based study. Int J Cancer, 136, 1921-30.

Zhao P, Chen WQ, Kong LZ (2012). Cancer Incidence and Mortality in China (2003-2007). Beijing: Military Medical Science Press.

Zhou Y, Cui Z, Zhou X, et al (2013). The presence of old pulmonary tuberculosis is an independent prognostic factor for squamous cell lung cancer survival. $J$ Cardiothorac Surg, 8, 123. 